\title{
Protanthomyza grimaldii sp. nov., a further member of the extinct subfamily Protanthomyzinae (Diptera, Anthomyzidae) from Baltic amber
}

\author{
Jindřich Roháček ${ }^{1}$ \\ I Silesian Museum, Nádražni okruh 31, CZ-746 01 Opava, Czech Republic \\ Corresponding author: Jindřich Roháček (rohacek@szm.cz)
}

Academic editor: Pavel Stoev | Received 24 February 2020 | Accepted 20 August 2020 | Published 5 October 2020

http://zoobank.org/6E1E443A-7374-4912-9462-E267B49EEA2E

Citation: Roháček J (2020) Protanthomyza grimaldii sp. nov., a further member of the extinct subfamily Protanthomyzinae (Diptera, Anthomyzidae) from Baltic amber. ZooKeys 973: 1-15. https://doi.org/10.3897/ zookeys.973.51435

\begin{abstract}
A new fossil species, Protanthomyza grimaldii sp. nov. (Diptera, Anthomyzidae), is described from Baltic amber (Eocene, 48-34 Ma) based on two (male and female) inclusions. It is the ninth species of the †genus Protanthomyza Hennig, 1965 and †subfamily Protanthomyzinae Roháček, 1998. Adult morphology of $P$. grimaldii sp. nov. revealed that the rich chaetotaxy of the thoracic pleuron, two anal veins and presence of the anteroventral process of the epandrium are plausibly shared by all species of Protanthomyza. Relationships of the new species, which belongs to a group lacking the ctenidial spine on the fore femur, are discussed.
\end{abstract}

\section{Keywords}

Anthomyzid flies, adult morphology, Eocene, new extinct species, relationships, taxonomy, Tertiary 


\section{Introduction}

Fossil taxa of Anthomyzidae (Diptera) were reviewed by Roháček (2013a), with one species subsequently added (Roháček 2014). A total of 12 ancient (all Tertiary) valid and named species belonging to four genera are currently recognized. The majority of fossil species of Anthomyzidae were described from Baltic amber (48-34 Ma) and only one, viz. Grimalantha vulnerata Roháček, 1998, originates from Dominican amber (Miocene, 18-16 Ma). Only four of the ancient species belong to the "modern" subfamily Anthomyzinae Czerny, 1903, viz. the above Grimalantha vulnerata from the Miocene (see Roháček, 1998) and Lacrimyza lacrimosa Roháček, 2013, L. christelae Roháček, 2013 and Reliquantha eocena Roháček, 2014 from the Eocene. The latter species belongs to a genus originally described by Roháček (2013b) for an extant species, $R$ variipes Roháček, 2013 from Great Britain. All remaining ancient Anthomyzidae are members of the exclusively fossil subfamily Protanthomyzinae Roháček, 1998 and belong to its only genus Protanthomyza Hennig, 1965. Eight named species of this genus are currently recognized, viz. P. collarti Hennig, 1965, P. hennigi Roháček, 2013, P. hoffeinsorum Roháček, 2013, P. krylovi Roháček, 2013, P. loewi Roháček, 2013, P. meunieri Roháček, 2013, P. presli Roháček, 2013 and $P$. tschirnhausi Roháček, 2013, all of which were treated in detail by Roháček (2013a). However, Roháček (2013a: 451) also presented the diagnosis of one more new species of Protanthomyza which was left unnamed due to insufficient material (a single female with some parts of the body obscured). This unnamed species was considered distinctly different from all other known members of the genus and, therefore, it was also counted among them for the estimation of species diversity of Anthomyzidae in the Eocene Baltic amber forest ecosystem (Roháček 2013a: 470). Recently, Mrs. Christel Hoffeins purchased a nicely preserved Protanthomyza inclusion and provided it for study. Detailed examination of this specimen revealed it to be the formerly unknown male conspecific with the unnamed "Protanthomyza sp. nov." female dealt with in Roháček (2013a). To supplement the latter monographic treatment, this new species is described in detail below, including the re-examination of the above female specimen. This is only the third fossil species of Protanthomyza (and the fourth of all ancient Anthomyzidae) in which both sexes are known.

\section{Material and methods}

\section{Material}

Two amber pieces with 2 anthomyzid inclusions were examined. Abbreviations of amber sources and depositories: AMNH - American Museum of Natural History, New York, USA; CCHH - collection of C. and H. W. Hoffeins, Hamburg, Germany; CMTB - collection of M. von Tschirnhaus, Bielefeld, Germany; SDEI - Senckenberg Deutsches Entomologisches Institut (Senckenberg German Entomological Institute) in Müncheberg, Germany. 


\section{Preparation of amber specimens}

The methods of preparation of amber stones with fly inclusions were described in detail by von Tschirnhaus and Hoffeins (2009). The amber specimens examined had already been cut out of the original stones, ground and polished as close and as parallel as possible to the frontal, dorsal and lateral sides of the fly and one of them had been subsequently embedded in artificial resin (also ground and polished) (Hoffeins 2001) to facilitate its stereoscopic investigation. This process left a significant cut portion of one stone bearing syninclusions, which remains deposited in $\mathrm{CCHH}$.

\section{Techniques of investigation}

The amber inclusions were examined, drawn and measured using two types of binocular stereoscopic microscopes (Reichert, Olympus). Legs were drawn on squared paper using a Reichert binocular microscope with an ocular screen. The specimens were either photographed by a Canon EOS 60D digital camera with Canon MP-E

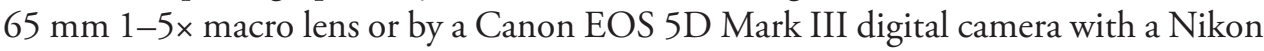
CFI Plan $10 \times / 0.25 \mathrm{NA} 10.5 \mathrm{~mm}$ WD objective attached to a Canon EF $70-200 \mathrm{~mm}$ f/4L USM zoom lens. The specimen photographed by means of the latter equipment was repositioned upwards between each exposure using a Cognisys StackShot Macro Rail and the final photograph was compiled from multiple layers (35) using Helicon Focus Pro 7.0.2. The final images were edited in Adobe Photoshop CS6. Some illustrations were drawn from these and some other macrophotographs and details were inked based on direct observation at higher magnification using a binocular microscope. Measurements: Six characteristics were measured - body length (measured from anterior margin of head to end of cercus, thus excluding the antenna), wing length (from wing base to wing tip), wing width (maximum width), index $C s_{3}: C s_{4}$ (= ratio of length of $3^{\text {rd }}$ costal sector : length of $4^{\text {th }}$ costal sector), index $r-m \backslash d m-c u: d m-c u$ (= ratio of length of section between $r-m$ and $d m-c u$ on cell $d m$ : length of $d m-c u$ ) and index $r-m \mid$ $d m-c u: C u A_{1}$ ( = ratio of length of section between $r-m$ and $d m-c u$ on cell $d m$ : length of apical portion of $\left.C u A_{1}\right)$.

Morphological terminology follows that used in Roháček $(2006,2009)$ and Roháček and Barber (2016), including terms of the male hypopygium to be in continuation with Roháček (2013a), except where "orbit" is replaced with "orbital plate". Male terminalia terminology is largely based on the "hinge" hypothesis of the origin of the eremoneuran hypopygium, re-discovered and documented by Zatwarnicki (1996) and, therefore, the following alterations of terms of the male genitalia (against those used by other hypotheses) need to be listed (terms used here first): epandrium $=$ periandrium, gonostylus $=$ surstylus. Morphological terms of the male abdomen and terminalia are depicted in Figs 8, 9, those of the female abdomen in Fig. 13. The synonymous morphological terms of adult structures and their abbreviations as used in the recent manual of Afrotropical Diptera (Cumming and Wood 2017) are given in parentheses in the list of abbreviations below. 
Abbreviations of morphological terms used in text and/or figures

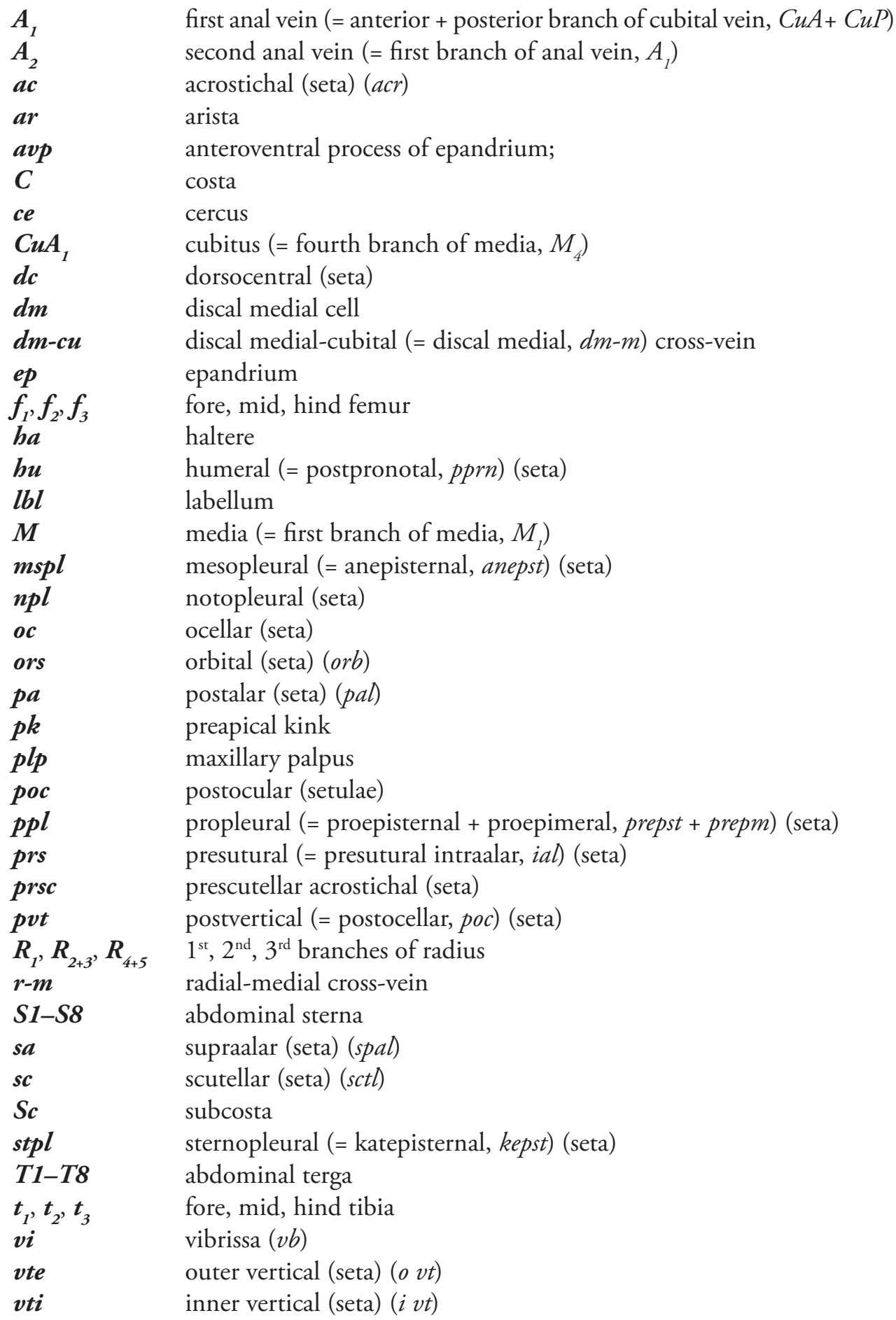




\section{Systematic palaeontology}

Class Insecta Linnaeus, 1758

Order Diptera Linnaeus, 1758

Superfamily Opomyzoidea Fallén, 1820

Family Anthomyzidae Czerny, 1903

Subfamily Protanthomyzinae Roháček, 1998

\section{Genus Protanthomyza Hennig, 1965}

Type species. Protanthomyza collarti Hennig, 1965; Baltic amber (Eocene).

\section{Protanthomyza grimaldii sp. nov.}

http://zoobank.org/D95A90D3-4F55-46E2-814A-4D8117555C47

Figures 1-14

Protanthomyza sp. nov.: Roháček 2013a: 451-452, fig. 7E, F (diagnosis, female only).

Etymology. The species is dedicated to Prof. Dr. David Grimaldi (New York, U. S. A.), the distinguished American dipterist and palaeontologist, in recognition of his valuable contribution to the knowledge of amber fossil flies, including acalyptrates (largely from Dominican amber).

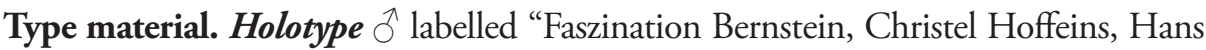
Werner Hoffeins" (framed on obverse), "1040-5a Diptera: Acalyptratae, Anthomyzidae đ"” (handwritten by C. Hoffeins, on reverse), "Baltic amber, Russia: Kaliningrad region, Yantarny", "obtained in May 2010 from Dr. Andrey Krylov, Kaliningrad, Russia”, and "Holotypus $\widehat{O}$, Protanthomyza grimaldii sp.n., J. Roháček det. 2020" (red label) [amber piece embedded in polyester resin, size $8.6 \times 7.9 \times 4.8 \mathrm{~mm}$ ], deposited in SDEI (inventory number Dip-00821). The original amber stone (in form of an icicle $=$ Zapfenschlaube in German), size about $45 \times 20 \times 11 \mathrm{~mm}$, with multiple layers and aggregation of inclusions, was cut in two pieces; that with the inclusion of $P$. grimaldii (No. 1040-5a) was separated, manually prepared and embedded in polyester resin by H. W. Hoffeins in August 2015. Syninclusions in 1040-5a: 1 stellate hair, pollen grains. Syninclusions in the remaining part (1040-5b, deposited in CCHH): Diptera: Empididae: 1 Rhamphomyia sp. female; 2 Mycetophilidae males + fragment; 1 Simuliidae; 2 Chironomidae female and male; Trichoptera, not identifiable; Coleoptera fragment; Araneae fragment; stellate hairs. Paratype $q$ labelled "47b-1, (Baltic A.), $15.1 \times 10.7 \times 3.3$ [mm]" (handwritten), "Protanthomyza sp.n. + , J. Roháček det. 2011" (yellow label) and "Paratypus + , Protanthomyza grimaldii sp.n., J. Roháček det. 2020" (yellow label) [shape of stone irregularly pentagonal, thin], temporarily held in CMTB; it will be deposited in AMNH. Syninclusions: only stellate hairs.

Type locality and age. Russia: Kaliningrad region, Yantarny mine. Middle to Late Eocene, 48-34 Ma (cf. Seyfullah et al. 2018). 
Diagnosis. Ocellar triangle delimited by a groove; frontal triangle not delimited; $1^{\text {st }}$ antennal flagellomere normal, not enlarged; arista bare; 3 or $4 d c$ macrosetae; $f_{1}$ without a ctenidial spine; male epandrium elongate and posteriorly tapered, with a robust, hook-like, curved anteroventral process; female T7 short; female S6 and S7 broadly transverse.

Description. Male (Figs 1, 2). Total body length ca $2.6 \mathrm{~mm}$; general colour brown to blackish brown; only head and some extremities partly ochreous to yellow.

Head (Figs 3-5) higher than long, anteriorly somewhat angularly protruding in front of eye margin (Fig. 5). Occiput very slightly concave, blackish brown. Frons relatively narrow, blackish brown only posteriorly around ocellar triangle, pale brown in anterior half to ochreous yellow at anterior marginal area surrounding frontal lunule. Frontal triangle not developed; ocellar triangle blackish brown, distinctly protruding and delimited by marginal groove. Ocelli large (Figs 3, 4). Orbital plate lighter (ochreous yellow) anteriorly, becoming pale brown posteriorly where contrasting with blackish-brown vicinity of ocellar triangle. Frontal lunule long, ochreous yellow. Face relatively narrow, ochreous, medially lighter and somewhat depressed; parafacialia and anterior half of gena dirty yellow and narrowly brown bordered (gena ventrally); posterior half of gena and postgena brown; mouthparts yellow to ochreous, clypeus pale brown, palpus dirty yellow. Cephalic chaetotaxy (Figs 4, 5): pvt (only left one visible) relatively short, convergent but not crossed; $v t i$ longest of cephalic setae, slightly inclinate; vte strongly exclinate and only slightly shorter than $v t i ; 3$ distinct ors, all slightly reclinate, posterior ors longest (about as long as vte), others becoming slightly shorter anteriorly; oc relatively thin (not longer than middle ors), proclinate (and unnaturally crossed in holotype), arising inside ocellar triangle; anterior half of frons with about 5 or 6 pairs of microsetae, mostly medially in front of ocellar triangle but a few (1 or 2) also between anterior and middle ors; vi distinct (Fig. 5), about 3 times as long as foremost peristomal setula; no subvibrissa; 4 or 5 weak proclinate peristomals; postocular setulae in two rows as usual but with only 3 setulae in inner row (Fig. 4); outer row of postoculars long, reaching ventral eye margin; postgena with 2 setae, anterior short, posterior longer. Palpus slender, elongate, with a few (3 visible) minute setulae distally (Fig. 5). Mouthparts relatively short. Eye bare, relatively large and strongly convex, suboval, anteriorly regularly rounded, with only posterior margin somewhat straighter; its longest diameter almost vertical and 1.16 times as long as shortest diameter. Gena low, its shortest height about 0.08 times as long as shortest eye diameter. Antenna medium-sized, generally porrect (Fig. 5) but directed anteroventrally to ventrally, with dark-brown basal segments and pale-brown to ochreous $1^{\text {st }}$ flagellomere. Pedicel with 1 longer seta and several microsetae; $1^{\text {st }}$ flagellomere oval, laterally compressed, with very short, dense and dark pilosity; arista about 1.8 times as long as antenna, entirely bare (Fig. 5), 2 basal segments slightly widened.

Thorax hardly narrower than head, brown to blackish brown, with shining mesonotum and duller pleural part. Mesonotum relatively convex, separated from scutellum by deep suture. Scutellum rounded subtriangular, wider than long, convex dorsally; postscutellum not visible. Thoracic chaetotaxy (see Figs 3, 4,7) rich as usual in 


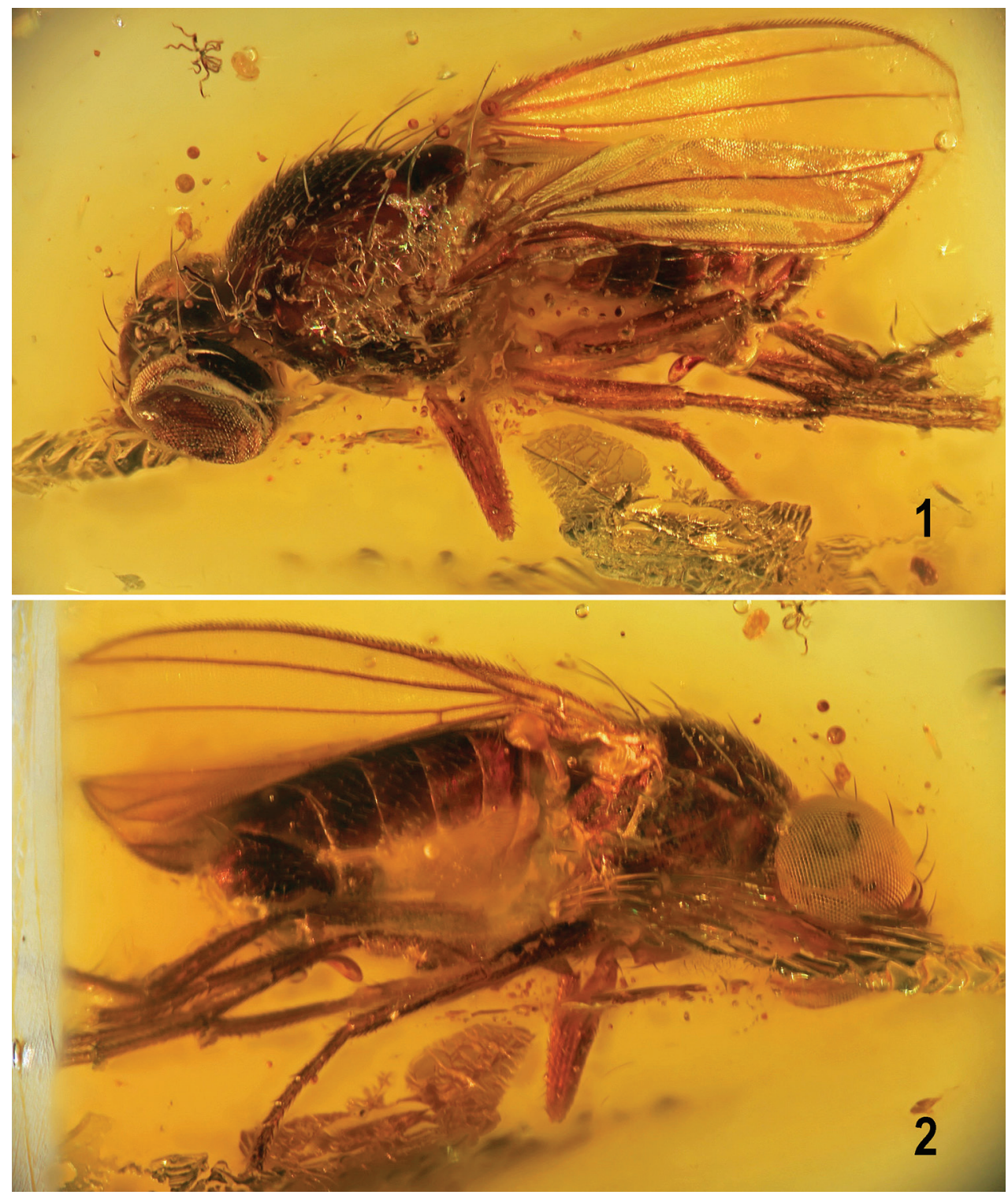

Figures I, 2. Protanthomyza grimaldii sp. nov., holotype male (Baltic amber) I entire specimen, left laterodorsal view 2 ditto, right lateroventral view. Body length ca $2.6 \mathrm{~mm}$. Photographs by J. Roháček.

the genus: 1 short $h u$ (markedly shorter than anterior $n p l$ ) and only 2 or 3 setulae on humeral callus (= postpronotal lobe); 2 long $n p l$, anterior slightly longer; 1 distinct $p$ rs (about as long as posterior $n p l)$; 1 long $s a ; 2 p a$, external very long (longer than $s a$ ), internal shorter (not visible on left side in Fig. 4); 3 or 4 postsutural $d c$ (number different on left and right sides) becoming shorter anteriorly, the hindmost longest (together with apical $s c$ longest thoracic setae); $a c$ microsetae dense, in 9 or 10 rows on suture, 


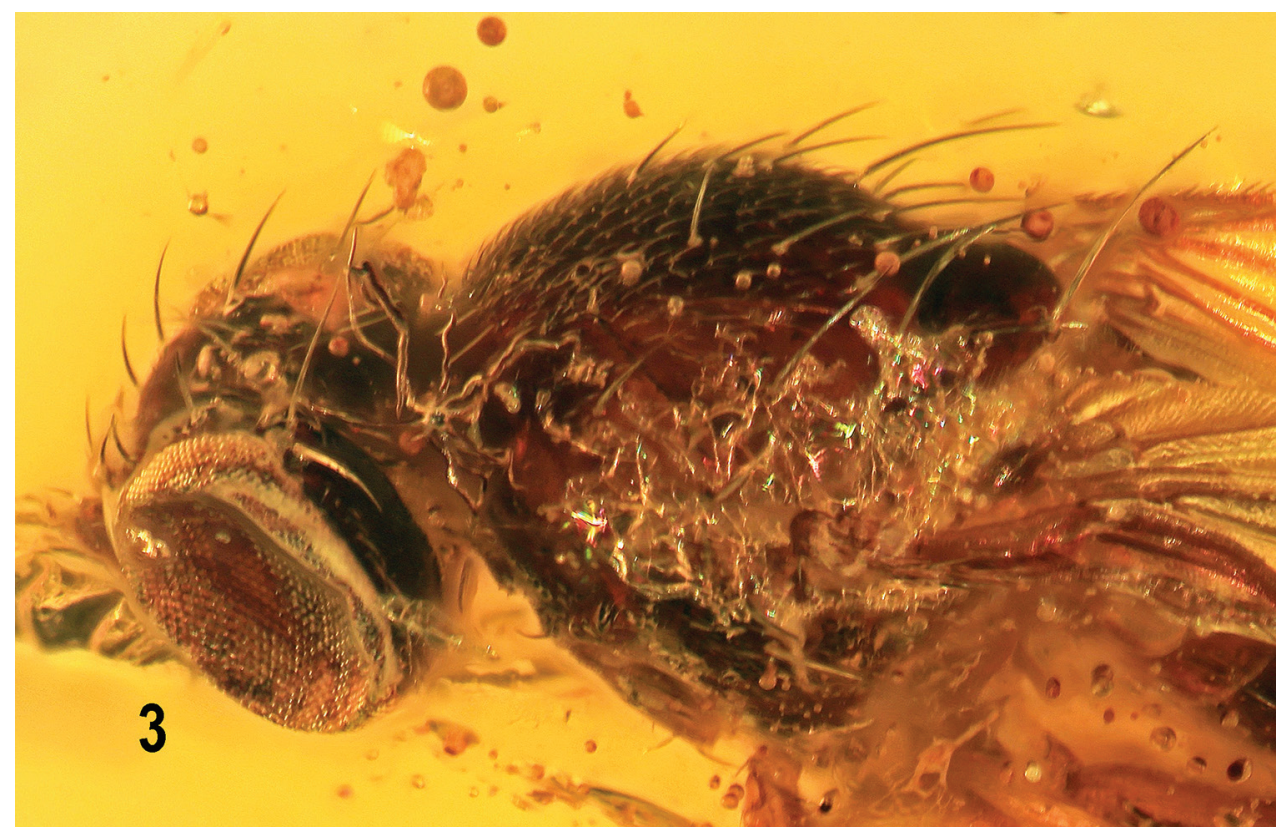

Figure 3. Protanthomyza grimaldii sp. nov., holotype male (Baltic amber). Head and thorax, left laterodorsal view. Photograph by J. Roháček.

those in medial rows reaching up to posterior $d c$; prescutellar $a c$ macrosetae long and strong, as long as $s a ; 2 s$, laterobasal shorter (about as long as $p r s$ ), apical very long; no additional setulae on scutellum; 2 upcurved $p p l$, anterior distinct (as long as $h u$ ), posterior small. Mesopleuron (anepisternum) and sternopleuron (katepisternum) setose (Figs 4, 7) as in most other species of Protanthomyza: 3 long mspl (1 dorsal upcurved and shortest, 1 posterodorsal and 1 posterior longest, cf. Fig. 7) and numerous setulae in posterodorsal half of mesopleuron; 1 long posterior $s t p l$ and about 9 or 10 setulae in posterior half of sternopleuron; other sclerites of pleural part of thorax bare.

Legs brown to ochreous, femora darkest, fore coxa pale ochreous. $f_{1}$ lacking ctenidial spine; 5 (2 longer) distinct widely-spaced setae in posterodorsal row; setae in posteroventral row more numerous but short and weak. $f_{2}$ with 2 or 3 anterior setae near middle (cf. Fig. 14), otherwise shortly setulose as is $f_{3} . t_{2}$ with distinct ventroapical seta (about as long as maximum width of $t_{2}$ ) and 2 or 3 small setae adjacent to the latter; $t_{l}, t_{3}$ and all tarsi simply setulose but basitarsi of all legs with ventrobasal setulae somewhat longer than others.

Wing (Figs 1, 6) moderately long and narrow, widest at distal third; veins brown to pale brown, membrane unicolourous, pale-brown tinged; $C$ with more or less distinct subcostal break and somewhat attenuated at humeral cross-vein. $C$ extended to apex of $M$, densely uniformly setulose on $C s_{2}$ (from subcostal break to apex of $R_{2+3}$ ), finely short-pilose more distally (on $C s_{3}$ and $C s_{4}$ ); $S c$ distinct, separate almost along its entire length, only apically fused with $R_{1}$ to form preapical kink (see Fig. 6, $p k$ ); $R_{1}$ short, dilated distally due to fusion with $S c ; R_{2+3}$ long, very slightly sinuate to almost straight 


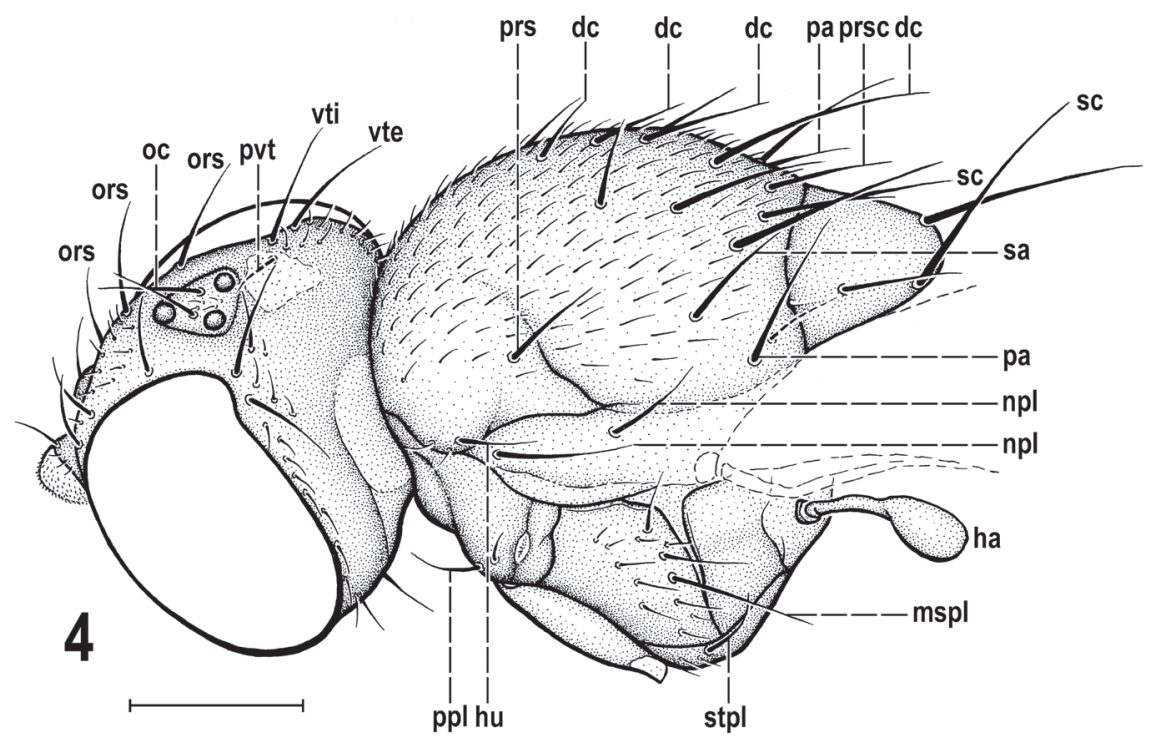

Figure 4. Protanthomyza grimaldii sp. nov., holotype male (Baltic amber). Head and thorax, left laterodorsal view. Scale bar: $0.3 \mathrm{~mm}$. For abbreviations see p. 4 .

and only its extreme apex slightly upcurved to $C ; R_{4+5}$ slightly recurved in distal half, divergent from $R_{2+3}$ and apically slightly convergent with $M ; M$ almost straight. Cell $d m$ of moderate length, narrow proximally and much widened distally, with angle of anterior outer corner obtuse while that of posterior outer corner distinctly acute (cf. Fig. 12); $r-m$ situated in basal third of cell $d m$; $d m-c u$ straight; apical portion of $C u A_{1}$ much shorter than distance between $r-m$ and $d m-c u$, distinctly longer than $d m-c u$ and almost reaching wing margin; $A_{1}$ relatively long but ending far from wing margin; $A_{2}$ well developed, slightly shorter than $A_{1}$ (Fig. 6); alula distinct but narrow (Fig. 6). Wing measurements: length ca $2.4 \mathrm{~mm}$, width ca $0.8 \mathrm{~mm}, C s_{3}: C s_{4}=1.38, r-m \backslash d m-$ $c u: d m-c u=3.50, r-m \backslash d m-c u: C u A_{1}=2.50$. Haltere (Figs 4, 8) pale ochreous, knob relatively large, darker dorsally.

Abdomen (Figs 1, 2, 8) relatively short, robust but not very broad. Preabdominal terga blackish brown; $T 1$ fused with $T 2$ but delimited by a groove (Fig. 8); T1 finely short-setose, T2-T5 with relatively long and dense setae (Fig. 8); T2 somewhat shorter than T3, T3-T5 subequal in length, all relatively short and transverse (Figs 2, 8). Preabdominal sterna mostly invisible (Figs 2, 8) but probably small (narrow) and pale-pigmented; only $S 5$ discernible (Fig. 8), paler brown and shorter than adjacent $T 5$, with sparse setae. Also 2 setae of $S 4$ visible on right side of abdomen (Fig. 8) but margins of sclerite are not recognizable. Postabdomen: $S 6$ and $S 7$ not visible because situated on obscured left side of abdomen (cf. Fig. 1), probably asymmetrical and (partly) fused together (dorsally also with S8) as in other Protanthomyza species (cf. Roháček 2013a, fig. $4 \mathrm{H}) . S 8$ relatively long, blackish brown, situated dorsally and readily visible on right side (Figs 2, 8), almost bare, with only a few setulae. 


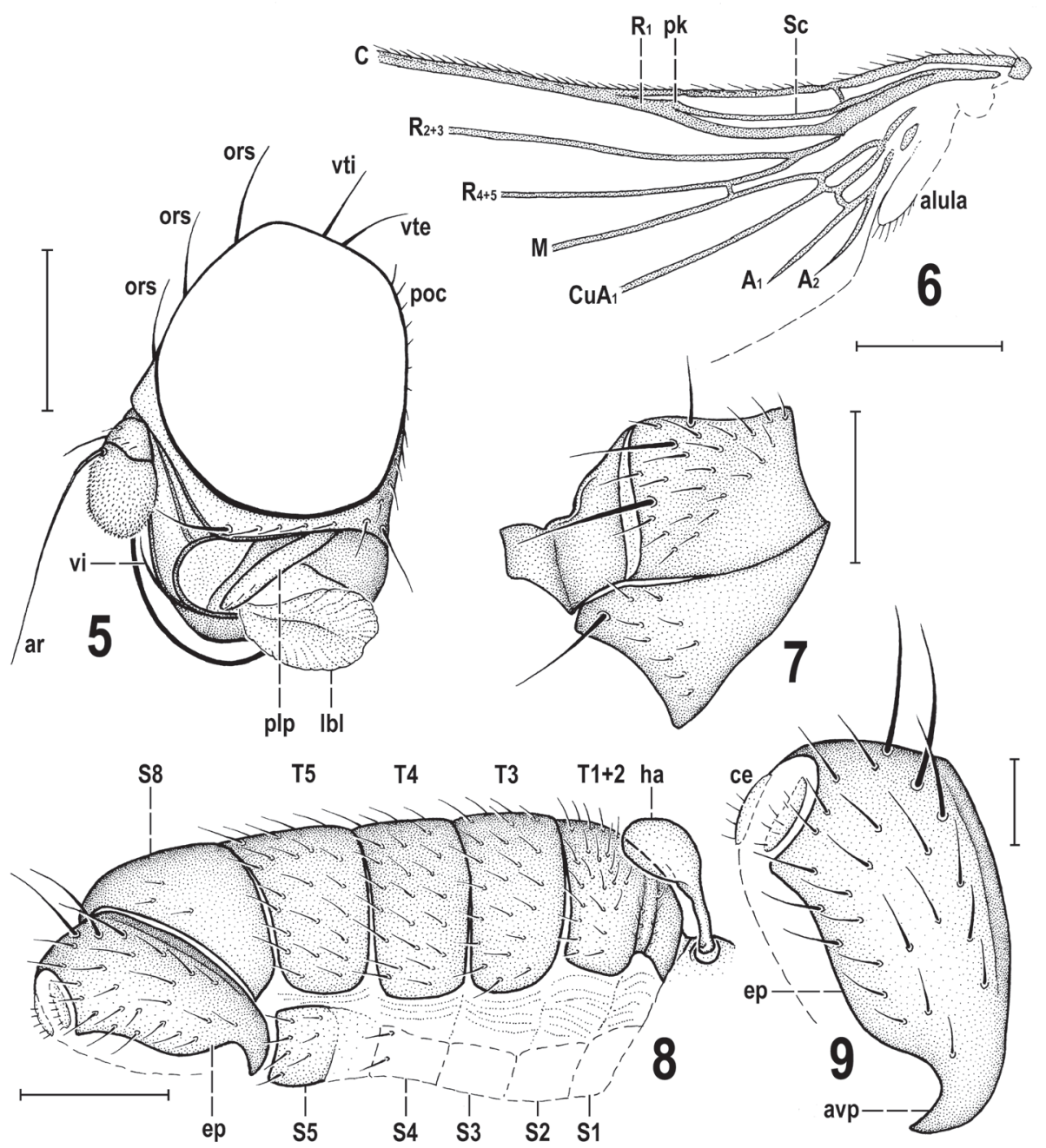

Figures 5-9. Protanthomyza grimaldii sp. nov., holotype male (Baltic amber) $\mathbf{5}$ head, left sublateral view $\mathbf{6}$ base of left wing $\mathbf{7}$ right mesopleuron, sternopleuron and pteropleuron, lateral view 8 abdomen and haltere, right lateral view 9 terminalia, right lateral view. Scale bars: $0.5 \mathrm{~mm}(\mathbf{5}) ; 0.3 \mathrm{~mm}(\mathbf{6 - 8}) ; 0.1 \mathrm{~mm}(\mathbf{9})$. For abbreviations see p. 4.

Genitalia. Epandrium (Figs 8, 9) relatively long but tapered posteriorly, with anteroventral corner modified to distinct, flat and somewhat hook-like projection (see Fig. 9, avp) distinctly different from those in other Protanthomyza species where known (cf. Roháček 2013a, figs 1F, 2E, 4H, 6B, 12C). Epandrium anterodorsally with 3 pairs of long erect setae (the most lateral markedly shorter), otherwise with scattered short setae. Anal fissure relatively small and cercus reduced (small and narrow) with fine short pubescence (Fig. 9). Gonostylus not discernible (on any side) but probably small and pale. No structures of internal genitalia visible. 

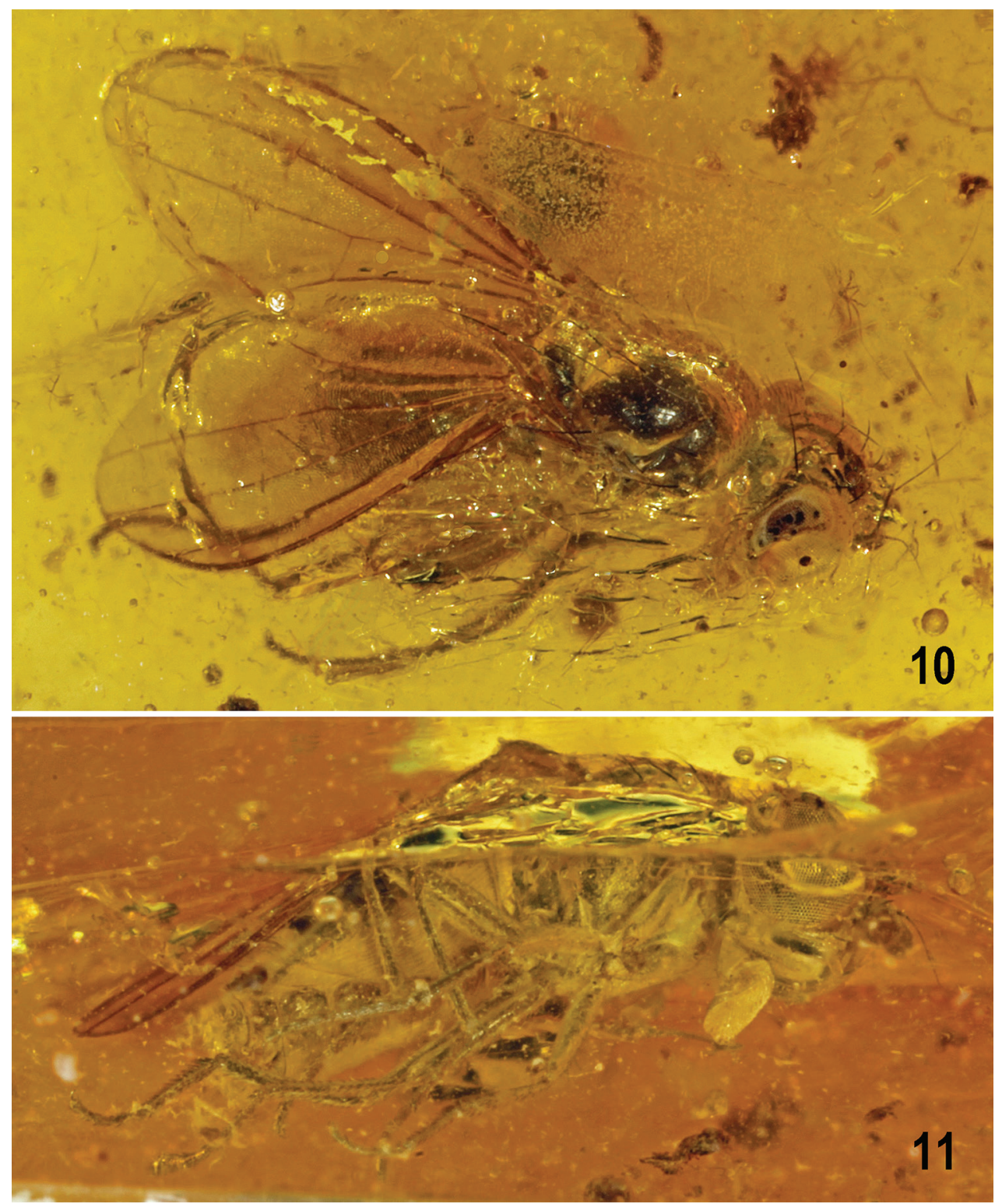

Figures I 0, II. Protanthomyza grimaldii sp. nov., female paratype (Baltic amber) 10 entire specimen, subdorsal view I I ditto, lateroventral view. Body length ca $2.9 \mathrm{~mm}$. Photographs by J. Roháček (adapted from Roháček 2013a, fig. 7E, F).

Female (Figs 10, 11). Similar to male unless mentioned otherwise. Total body length ca $2.9 \mathrm{~mm}$. pvt short, strongly convergent, with apices meeting medially; $o c$ proclinate and divergent; setae in posteroventral corner of postgena subequal. Palpus with more setulae (5 or 6) visible ventrally, subapically and apically. Mesonotum with 3 strong $d c$ in left row and with $4 d c$ ( 2 posterior strong, 2 anterior short and 

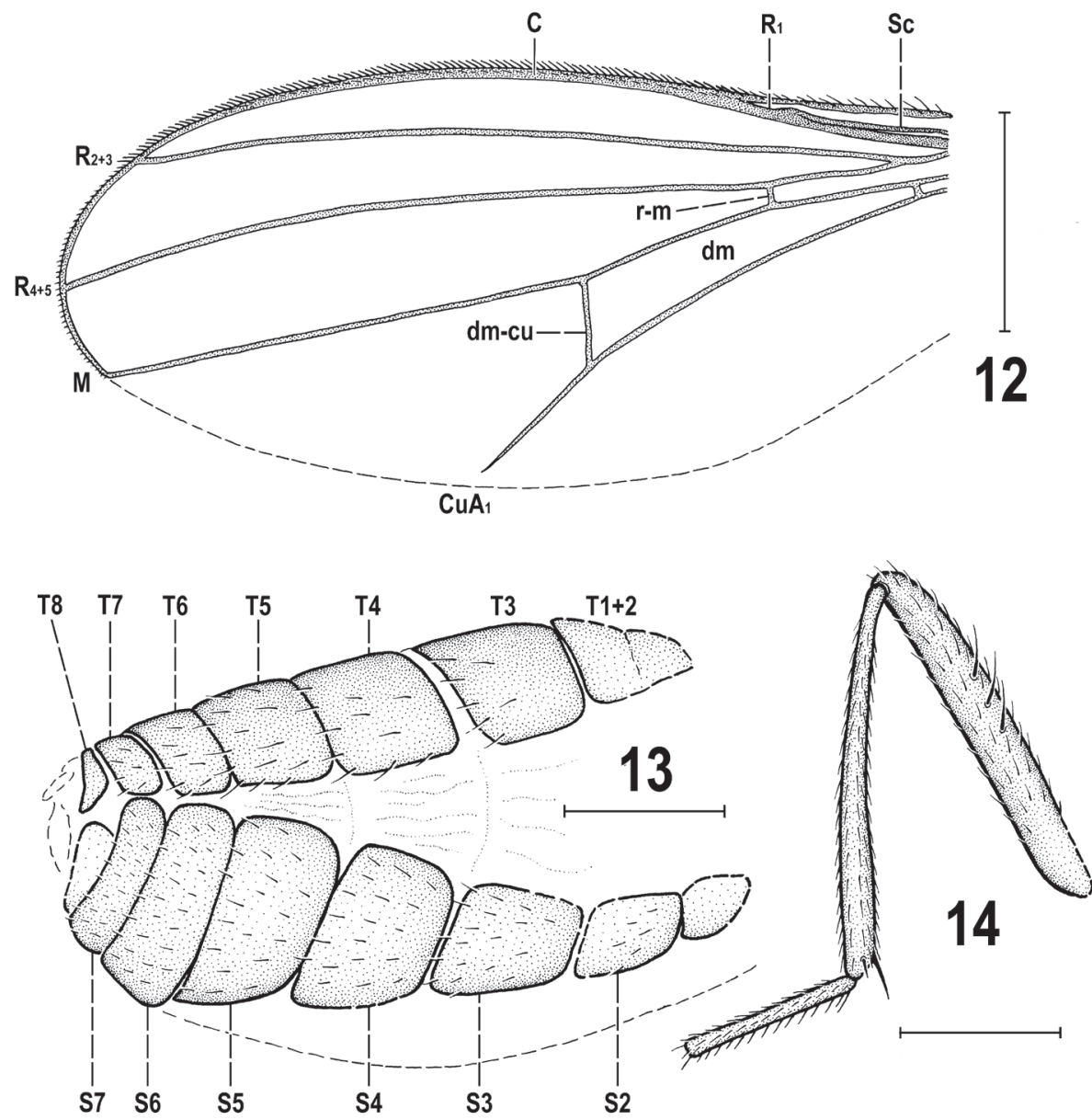

Figures I2-14. Protanthomyza grimaldii sp. nov., female paratype (Baltic amber) I 2 left wing (invisible parts omitted) $\mathbf{3}$ abdomen, right lateroventral view $\mathbf{1} \mathbf{4}$ right $\mathrm{f}_{2}, \mathrm{t}$ and mid basitarsus, anterior view. Scale bars: $0.5 \mathrm{~mm}(\mathbf{I}), 0.3 \mathrm{~mm}(\mathbf{I 3}, \mathbf{I 4})$. For abbreviations see p. 4.

weaker) in right row; prescutellar $a c$ macrosetae longer than $s a$; about 8 rows of $a c$ microsetae on suture. Legs more slender but with same chaetotaxy as in male, except $\mathrm{t}_{2}$ (Fig. 14) with ventroapical seta longer. Wing (Fig. 12) venation resembling that of male but cell $d m$ shorter and cross-vein $\mathrm{r}-\mathrm{m}$ situated more distally. Wing measurements: length $2.58 \mathrm{~mm}$, width $0.95 \mathrm{~mm}, C s_{3}: C s_{4}=1.44, r m \backslash d m-c u: d m-c u=2.37$, rm $\backslash d m-c u: C u A_{1}=1.97$.

Abdomen (Figs 11, 13) only partly visible. Preabdomen with terga $(T 1+2, T 3-T 5)$ obviously darker brown than sterna, relatively narrow, hence pleural part of preabdominal segments large; setae on T3-T5 (and also on T6 and T7) longer than those 
on adjacent sterna. Preabdominal sterna pale brown to ochreous. S1-S5 becoming distinctly wider posteriorly, $S 5$ widest and largest.

Postabdomen. T6 distinctly shorter than T5, transverse; $T 7$ yet shorter and also narrower than T6. S6 strikingly broad and transverse, wider but shorter than $S 5$ and apparently larger than adjacent $T 6$ and laterally almost reaching the latter; $S 7$ only half length of S6, strongly transverse and laterally meeting with sides of T7 (Fig. 13); both $S 6$ and S7 finely setulose. Apex of postabdomen obscured, only T8 discernible as small bare(?) sclerite (Fig. 13), less than half length of T7. Cercus not visible.

\section{Discussion}

Protanthomyza grimaldii sp. nov. was previously recognized as a new species by Roháček (2013a: 451) but left unnamed because of insufficient material (a single female having a number of characters not visible). Thanks to the efforts of Christel Hoffeins, a male specimen conspecific with this female was recently obtained for examination and enabled the description and naming of this species. This is the third species of Protanthomyza where both sexes are known; formerly, the male and female were described only in P. krylovi (1 male and 2 females found in one piece of Baltic amber) and $P$. tschirnhausi (1 male and 1 female in separate pieces of Bitterfeld amber), see Roháček (2013a).

Protanthomyza grimaldii belongs to a group of species lacking a ctenidial spine on the fore femur and both sexes are correctly keyed by Roháček (2013a: 442, as $P$. sp. nov.). With its bare arista and generally similar chaetotaxies of the head and thorax, it most closely resembles $P$. loewi (known only from the female), which could be its nearest relative. However, $P$. grimaldii can be easily distinguished from $P$. loewi by the distinctly smaller $1^{\text {st }}$ flagellomere of the antenna (Fig. 5, cf. Roháček 2013a, fig. $8 \mathrm{~B}$ ), the ocellar triangle delimited by a groove (Fig. 4), the less elongate wing with more divergent $R_{2+3}$ and $R_{4+5}$ (Fig. 12, cf. Roháček 2013a, fig. 7D) and the shorter and wider female abdomen with short T7 and broadly transverse S6 and S7 (Fig. 13, cf. Roháček 2013a, fig. 8A), apart from other smaller dissimilarities in head colouration, length of $p p l$ setae, $f_{1}$ and $t_{2}$ chaetotaxy, etc. In the male, $P$. grimaldii differs from all five other species where the male is known (cf. Roháček 2013a) by the elongate and posteriorly tapered epandrium with a robust, hook-like, curved anteroventral process (Fig. 9, avp). Only in P. tschirnhausi is the epandrial process similarly robust and flat but it is simply triangular (not hooked) and the epandrium is short, almost globose (not elongate) (cf. Roháček 2013a, fig. 12C). Moreover, P. tschirnhausi differs markedly from $P$. grimaldii in a number of other characters including the ciliate arista, very large eyes, only $2 d c$ and a strong ctenidial spine on $f_{I}$, see Roháček (2013a). Unfortunately, the male of $P$. loewi remains unknown and, consequently, the previously suggested relationship of that species with $P$ grimaldii cannot be confirmed by examination of characters of the male terminalia. 


\section{Conclusions}

Based on the data presented above, it can be concluded that:

(1) P. grimaldii is the ninth named species of the genus Protanthomyza, making this genus the most species-rich fossil genus of Anthomyzidae.

(2) The description of a new Protanthomyza species extends the morphological diversity evident in the male and female terminalia of this genus. This adds to the previously documented wide morphological diversity among species seen in the head structures, chaetotaxies, and formation of the sclerites of the abdomen besides the male and female terminalia.

(3) Two anal veins $\left(A_{1}, A_{2}\right)$ can continue to be treated as a subfamily/generic character for Protanthomyzinae and Protanthomyza, respectively.

(4) The chaetotaxy of the mesopleuron (usually with 3 posterior mspl macrosetae + numerous setulae more anteriorly) and sternopleuron (with 1 posterior stpl macroseta + setulae) seems to be rather uniform within the genus, although in a few species some setulae on the mesopleuron can be enlarged and/or one (usually the dorsal) $m s p l$ macroseta is reduced (cf. Roháček 1913a).

(5) The anteroventral process of the epandrium is a synapomorphic character of Protanthomyza. It is expected that this process will be found in all other species where the male is unknown, viz. in $P$. loewi, $P$. meunieri and $P$. presli.

\section{Acknowledgements}

I am very grateful to Mrs Christel Hoffeins (Hamburg, Germany) and Dr Michael von Tschirnhaus (Bielefeld, Germany) for making interesting amber specimens available for examination. Dr Andrey Krylov (Kaliningrad, Russia) is thanked for his continuing support with Baltic amber Diptera, especially acalyptrates, and Mr Peter Chandler (Melksham, England, UK) and both reviewers for their comments, improvements and language corrections of the manuscript. This research on fossil Anthomyzidae was supported by the Ministry of Culture of the Czech Republic, with institutional financing of the long-term conceptual development of the research institution (the Silesian Museum, MK000100595).

\section{References}

Cumming JM, Wood DM (2017) 2. Adult morphology and terminology. In: Kirk-Spriggs AH, Sinclair BJ (Eds) Manual of Afrotropical Diptera (Vol. 1). Introductory chapters and keys to Diptera families. Suricata 4. - South African National Biodiversity Institute, Pretoria, $89-133$.

Czerny L (1903) Revision der Heteroneuriden. Wiener Entomologische Zeitung 22: 61-107. 
Fallén CF (1820) Opomyzides Sveciae. Quarum desriptionem Venia Ampl. Facult. Philos. Lund. in Lyceo Carolino d. XXXI Maji MDCCCXX. Berlingianis Lundae [= Lund], 12 pp. Hennig W (1965) Die Acalyptratae des Baltischen Bernsteins und ihre Bedeutung für die Erforschung der phylogenetischen Entwicklung dieser Dipteren Gruppe. Stuttgarter Beiträge für Naturkunde 145: 1-215.

Hoffeins HW (2001) On the preparation and conservation of amber inclusions in artificial resin. Polskie Pismo Entomologiczne 70: 215-219.

Linnaeus C (1758) Systema Naturae per Regna Tria Naturae, Secundum Classes, Ordines, Genera, Species, cum Caracteribus, Differentiis, Synonymi, Locis. Editio decima, reformata (Vol. 1). L. Salvii, Holmiae, 824 pp. https://doi.org/10.5962/bhl.title.542

Roháček J (1998) Taxonomic limits, phylogeny and higher classification of Anthomyzidae (Diptera), with special regard to fossil record. European Journal of Entomology 95: 141-177.

Roháček J (2006) A monograph of Palaearctic Anthomyzidae (Diptera) Part 1. Časopis Slezského Zemského Muzea, Opava (A) 55(supplement 1): 1-328.

Roháček J (2009) A monograph of Palaearctic Anthomyzidae (Diptera) Part 2. Časopis Slezského Zemského Muzea, Opava (A) 58(supplement 1): 1-180.

Roháček J (2013a) New amber fossil Anthomyzidae (Diptera): an unexpected Eocene diversity. Journal of Systematic Palaeontology 11: 431-473. https://doi.org/10.1080/14772019.20 12.691907

Roháček J (2013b) Reliquantha variipes gen. \& sp. nov., a peculiar new taxon of Anthomyzidae (Diptera) from Great Britain with uncertain relationships. Acta Entomologica Musei Nationalis Pragae 53: 793-814.

Roháček J (2014) Reliquantha eocena sp. nov., first tertiary representative of an extant genus of Anthomyzidae (Diptera). Acta Entomologica Musei Nationalis Pragae 54: 773-784.

Roháček J, Barber KN (2016) Nearctic Anthomyzidae: a monograph of Anthomyza and allied genera (Diptera). Acta Entomologica Musei Nationalis Pragae 56 (supplementum): 1-412. Seyfullah LJ, Beimforde C, Dal Corso J, Perrichot V, Rikkinen J, Schmidt AR (2018) Production and preservation of resins - past and present. Biological Reviews 93: 1684-1714. https://doi.org/10.1111/brv.12414

von Tschirnhaus M, Hoffeins C (2009) Fossil flies in Baltic amber - insights in the diversity of Tertiary Acalyptratae (Diptera, Schizophora), with new morphological characters and a key based on 1,000 collected inclusions. Denisia 26: 171-212.

Zatwarnicki T (1996) A new reconstruction of the origin of eremoneuran hypopygium and its implications for classification (Insecta: Diptera). Genus 7: 103-175. 